\title{
AS CIÊNCIAS SOCIAIS E O INGLÊS
}

\section{Renato Ortiz}

A globalização declina-se preferencialmente em inglês. Digo, preferencialmente, pois a presença de outros idiomas é constitutiva de nossa contemporaneidade, mesmo assim, uma única língua, entre tantas, detém uma posição privilegiada. Há razões objetivas para que as coisas tenham se passado dessa maneira, e elas nada têm a ver com os fundamentos fonéticos ou gramaticais, seria tolice pensar a existência dos idiomas de forma substancialista (embora muitos o tenham feito). Os lingüistas ensinam-nos que toda linguagem é capaz de exprimir em conceitos a experiência humana, assim nenhuma delas é superior às outras. Sabemos ainda que somente os humanos possuem uma linguagem coerentemente articulada num sistema complexo de signos e que a diversificação das línguas é algo que ocorreu muito cedo nas so-

Artigo recebido em agosto/2003 Aprovado em novembro/2003 ciedades passadas. Independentemente das hipóteses disponíveis, e não confirmadas, sobre a origem da linguagem - monogenese ou poligenese -, a verdade é que, uma vez em atividade, elas evoluíram em comunidades separadas, espalhando-se por diversas regiões do planeta (existem atualmente algo em torno de 6.500 línguas faladas no mundo). Levando-se em consideração essa diversidade e o fato da impossibilidade de existir uma língua universal - para isso seria necessário que todas as experiências humanas convergissem para uma única fonte de sentido - seria insensato balizar nossa discussão na premissa de um mundo unívoco. O processo de globalização não é sinônimo de homogeneização, tampouco de americanização, trata-se de uma condição na qual as hierarquias e as linhas de força certamente existem, são desiguais, mas não implicam necessariamente a eliminação das diversidades. Nesse sentido, o desaparecimento das línguas nacionais, idealizado 
por alguns, como equivalente à irmandade universal (assim pensava Kautsky e muitos intelectuais da II Internacional), e por outros, como um pesadelo, é um falso problema. Não obstante, esta nota introdutória de cautela pouco esclarece sobre a temática em pauta, pois não é a unicidade das línguas que se encontra em causa, mas o fato de elas participarem de uma situação de globalização marcada por relações de poder.

O leitor diligente, paciente, percebe que boa parte de toda uma literatura relacionada à dispersão do inglês no mundo é relativamente recente. Ela se desenvolveu particularmente no final dos anos de 1970 e durante a década de 1980, quando foi publicada uma série de livros sobre sua difusão em escala internacional. ${ }^{1}$ Seus autores queriam documentar empiricamente a presença da língua inglesa em vários países e esferas de atividade - da ciência à publicidade - e também compreender as razões que a levaram a ocupar tal lugar de preponderância. Dois elementos chamam a atenção nesse tipo de estudo. O primeiro, relativo ao standard. Acostumados à existência de referências consagradas, os padrões britânico e norteamericano, a difusão do inglês levantava um problema, qual seja, como entender as variações idiomáticas existentes em países de língua oficial inglesa que não se encaixavam no modelo. Seria mais apropriado utilizar a expressão, "inglês ou ingles(es)", singular ou plural?² Kachru, um lingüista indiano, considera que a nativização do inglês teria como resultado a criação de um modelo autônomo, original, distinto do legado britânico, mas igualmente válido. Outros extrapolam sua metodologia de investigação, aplicando-a a diferentes regiões da Ásia, o que significa equiparar a legitimidade das variedades regionalmente desenvolvidas às matrizes exportadoras, Inglaterra e Estados Unidos (Kachru, 1982; Parakram, 1995). Entre os países de língua inglesa há portanto uma disputa sobre a existência ou não de um único padrão (ou no máximo dois) capaz de ordenar a hierarquia das falas. O debate sobre o standard, predominante entre os professores de língua estrangeira (eles buscam o "melhor" para suas atividades pedagógicas, reiterando sempre a excelência norteamericana e britânica), fundamenta-se num equívoco, cujo ocultamento tem dividendos políticos e culturais. Trata-se da afirmação de uma hegemonia travestida em verdade lingüística. Esta é uma discussão antiga. Desde a formação do Estado-nação, no qual o monopólio da língua foi um dos traços definitivos no processo de integração nacional, a exigência de uma referência generalizada a todos tem o intuito de se contrapor às outras falas existentes. Bourdieu recorda que a Revolução Francesa tinha como meta a imposição de uma língua legítima contra os idiomas e os dialetos regionais: "o conflito entre o francês da intelligentsia revolucionária e os idiomas é um conflito sobre o poder simbólico, cujo objetivo é a formação das estruturas mentais. Não se trata apenas de se comunicar, mas de reconhecer um novo discurso de autoridade" (Bourdieu, 1982, p. 31). Essas tensões não se situam apenas no passado, recorrentemente se atualizam diante da proliferação de idiomas conflitantes no seio de uma área geográfica comum. É o que ocorre nos Estados Unidos, onde o movimento English Only, árduo defensor do monolingüismo, tem como pretensão desqualificar e limitar a demanda dos imigrantes por uma educação bilíngüe (Willey e Lukes, 1996). No caso do inglês como língua internacional, a disputa em torno da autoridade não se confina às fronteiras de uma nação, ela envolve países com histórias e culturas diferenciadas, entretanto os termos da discussão são semelhantes, afinal o padrão postulado não tem nenhuma realidade empírica, é simplesmente um construto imaginado por aqueles que detém uma posição de poder, conferindo-lhes uma certa capacidade, qual seja, a de "corrigir" os outros. Invoca-se sua existência como justificativa de controle e de salvaguarda do idioma originário. A polêmica em torno da existência ou não de um padrão ocorre sobretudo quando há um campo de disputa no qual estão envolvidos os falantes. Por isso, ainda hoje, em momentos de tensão (situação de globalização), ela ressurge com força, e muitas vezes com os sinais trocados. Por exemplo, a controvérsia desencadeada em torno da Lei Toulon, que regulamentou oficialmente a utilização dos termos estrangeiros pela língua francesa. Aqui, a noção de padrão é recuperada como um estágio anterior de "pureza" que estaria sendo ameaçado e corrompido pelo uso excessivo do inglês (Durand, 1996). 
Um segundo aspecto diz respeito à dimensão anglo-cêntrica desses estudos e, muitas vezes, ao manto ideológico no qual estão envolvidos. Eles vêm marcados por um profundo otimismo e um indisfarçável sentimento de superioridade, como se a expansão de uma língua fosse realmente sinônimo de civilização e progresso. Diante do quadro inegável das evidências empíricas, repete-se com orgulho - no other language has undergone similar expansion since Greek and Roman times. Faltam a essas análises um mínimo de espírito crítico induzindo-nos a pensar que a magnitude de uma língua deve-se unicamente às estratégias diglóssicas dos falantes. O argumento principal, subjacente a essa corrente teórica, pode ser resumido da seguinte maneira: uma segunda língua é aprendida unicamente quando o falante estima que pode obter vantagens em utilizar outro idioma, cujo raio de atuação é mais amplo. Cito uma dessas pesquisas elaboradas na época. Os autores, após enumerarem um conjunto de fatores que eventualmente poderiam influir na difusão do inglês - atitude política, religião, urbanização, desenvolvimento econômico, diversidade lingüística, presença militar - concluem:

Dizer que o inglês está se difundindo no mundo em função de uma combinação de variáveis é uma afirmação sumária, fundada nas inúmeras interações e motivações humanas. São os indivíduos, e não os países, que aprendem inglês como segunda língua. E eles o fazem, não por causa de abstrações, como a diversidade lingüística ou a balança de pagamento, mas porque o conhecimento do inglês os ajuda a comunicar num determinado contexto, no qual, por razões econômicas, educacionais ou emocionais, eles desejam se comunicar com os outros e a oportunidade de aprender inglês encontra-se disponível. As estatísticas aqui utilizadas revelam algumas simetrias e regularidades, mas não podemos esquecer que o comportamento humano as antecedem. Portanto, o estudo da difusão das línguas deve proceder, não tanto da manipulação e da análise de dados abstratos e sumários, mas da observação direta do comportamento humano. [...] Os dados de um contexto específico devem por isso ser considerados dados secundários, na verdade muito distantes da arena cotidiana na qual as línguas são aprendidas e abandonadas (Fishman, Cooper e Rosenbaum, 1977, p. 106).
O uso do inglês decorreria assim das vantagens que proporciona aos que dele se utilizam. Seu estatuto é portanto de neutralidade, funcionando sobretudo como meio de comunicação mais abrangente. Lingüistas com diferentes inclinações teóricas, neste ponto, convergem para um mesmo diagnóstico. É o caso de Kachru, ferrenho opositor à idéia da existência de um padrão britânico ou norte-americano. Quando se trata de entender sua presença na Índia, em contraposição a outros idiomas existentes, ele nos diz: "O inglês tem uma clara vantagem lingüística: no contexto das línguas nativas, dialetos e estilos que muitas vezes se revestem de uma conotação indesejável, ele adquiriu uma neutralidade lingüística [...]"(apud Pennycook, 1998, pp. 9-10). O que é evidentemente ilusório, pois o seu uso na Índia é marcado por contradições políticas e controvérsias ideológicas (Sonntag, 2000). Importa, porém, ressaltar que o argumento anterior, o da neutralidade funcional, é reiterado. Nessa perspectiva, a expansão do inglês não seria simplesmente algo a ser comprovado, mas um benefício para todos. Os lingüistas parecem raciocinar como os antropólogos culturalistas dos anos de 1940, os quais supunham que o processo de aculturação derivava exclusivamente do contato entre duas culturas diferentes, independentemente do contexto no qual a interação se dava. Assim, as explicações relativas ao sincretismo religioso, ao messianismo africano, nada tinham a ver com a situação colonial dos atores envolvidos, fatos dessa natureza eram vistos como externos, alheios ao que estava acontecendo. ${ }^{3}$ Por isso, entre os antropólogos culturalistas, assim como entre os lingüistas, colonialismo e imperialismo são temas tabus, afinal, em última instância, eles teriam uma relação de exterioridade ao que se buscava entender.

Mas as reflexões sobre o inglês se tornam mais problemáticas quando a elas se agregam os escritos de caráter propriamente ideológico. Lembro, entre outros, o livro de Jeremy Tunstall, The media are American. Com uma farta documentação factual - relativa à televisão, ao cinema, à publicidade e à imprensa -, ele buscava entender o predomínio norte-americano no mundo. Suas considerações são exemplares: 
O inglês é provavelmente a língua mais influenciada e afinada ao uso dos meios de comunicação [...]. A mídia em inglês está relativamente isenta da separação entre as formas alta e vulgar - comparada ao alemão [...]. Também no inglês há uma pequena defasagem entre as formas escrita e falada [...]. Como língua, o inglês evoluiu com e através dos meios de comunicação, particularmente a imprensa [...]. O inglês contém a maior variedade de frases incisivas e de palavras simples, que podem ser escolhidas para o uso dos meios de $\mathrm{CO}^{-}$ municação, comparado, por exemplo, ao francês; a versão em língua inglesa é normalmente mais abreviada do que qualquer outra língua. O inglês tem também a gramática mais simples do que qualquer outro idioma concorrente, como o russo. A língua inglesa é a que melhor se adapta a histórias em quadrinho, manchetes de jornais, frases de efeito, subtítulos de fotos, canções pop, gracejos de disc-jockey, flash e músicas para comerciais (Tunstall, 1977, pp. 127-128).

Já não se trata apenas de neutralidade comunicativa ou vantagens diglóssicas, o inglês, em sua "essência", seria intrinsecamente superior aos outros idiomas. Língua da racionalidade e da modernidade, ele seria a razão primeira, e não a expressão, da supremacia norte-americana (muito dessa ideologia ainda se manifesta no senso comum em tempos de globalização). A forte reação a esta abordagem aparentemente ingênua, mas no fundo altamente interessada de análise, deve ser levada em conta, e a meu ver ela teve implicações importantes, positivas, na compreensão da problemática atual. Nesse sentido, o livro de Robert Phillipson, Linguist imperialism (1992), possui o mérito de introduzir no debate novos parâmetros, particularmente o papel que o colonialismo e o imperialismo tiveram na configuração do mundo atual. O legado colonial, associado à expansão do capitalismo, não se resumiria assim a questões de ordem meramente econômica, suas implicações se estenderiam a um domínio até então excluído, pelos lingüistas, de sua esfera de influência. O texto de Phillipson abre a possibilidade para que outros escrevam sobre o inglês "como ideologia", fazendo com que as razões de sua expansão deixem de ser encontradas em suas propriedades internas ou na mera interação entre os participantes da fala. É justamente esta dimensão, vista antes como exterioridade - a organização política, econômica e militar dos interesses, considerada irrelevante ou secundária para o entendimento analítico -, que se torna decisiva para a explicação. David Crystall, há muito interessado pela dispersão do inglês no mundo, escrevendo um pouco mais tarde, e de uma certa forma revendo seu ponto de vista anterior, pode então dizer:

Uma língua não se torna global por causa de suas propriedades estruturais, pelo tamanho de seu vocabulário, por ser veículo de uma grande literatura do passado, ou ter sido associada a uma grande cultura ou religião [...]. Uma língua torna-se internacional por uma razão maior: o poder político de seu povo - especialmente seu poderio militar [...]. Mas o domínio internacional de uma língua não decorre apenas da força militar. O poder militar de uma nação pode impor uma língua, mas é necessário um poderio econômico para mantêla e expandi-la [...]. O crescimento dos negócios e de uma indústria competitiva trouxe uma explosão internacional do marketing e do business [...]. A tecnologia, na forma do cinema e dos discos, canalizou as novas formas de entretenimento de massa, o que teve um impacto mundial. O impulso no progresso da ciência e da tecnologia criou um ambiente internacional de pesquisa, conferindo ao conhecimento acadêmico um grau elevado de desenvolvimento. Qualquer língua, no centro dessa explosão de atividades internacionais, repentinamente, teria sido alçada a um status global (Crystal, 1997).

A leitura dessa literatura permite-nos ainda formular uma pergunta. Em que medida ela se destaca, ou não, do debate sobre a globalização. Há alguma discrepância conceitual entre as afirmações "o inglês como língua internacional" e "o inglês como língua global", ou seriam elas fruto de imprecisões terminológicas sem maiores conseqüências. Acredito que diferenças substantivas existem, e é importante sublinhá-las. Há primeiro uma expressiva desconexão entre os estudos elaborados e os textos sobre a globalização, embora boa parte deles sejam contemporâneos. ${ }^{4}$ Porém, não se pode esquecer que durante os anos de 1980 e início dos de 1990 a reflexão sobre a globalização ficou confinada a alguns domínios es- 
pecíficos - publicidade e administração de empresas (refiro-me à literatura sobre marketing global). As ciências sociais dedicava-lhe pouca ou nenhuma atenção, sendo que o campo das idéias se encontrava polarizado entre modernos e pósmodernos, Habermas versus Lyotard. Mesmo o livro de Phillipson, publicado em 1992, não escapa a esta observação, uma vez que se fundamenta na tradicional definição de imperialismo (Hobson, Lenin), abrindo-se para algumas incorporações dos teóricos da dependência - a globalização encontra-se excluída dessa discussão. Por outro lado, chama a atenção nos trabalhos elaborados pelos lingüistas a presença constante de dois termos: difusão e dispersão - sintomaticamente um dos textos-chave sobre o assunto intitula-se The spread of english. Creio que neste ponto a comparação com os antropólogos pode ser recuperada, mas, agora, em relação ao difusionismo. ${ }^{5}$ Kroeber dizia que a

[...] difusão é o processo pelo qual os elementos ou os sistemas de cultura se espalham. Evidentemente ela está ligada à tradição, uma vez que a cultura material passa de um grupo para outro. Porém, como é usualmente entendida, a tradição se refere à transmissão de conteúdos culturais, de uma geração para a outra (dentro do mesmo grupo de população); a difusão se faz de uma população para outra. A tradição opera essencialmente em termos de tempo, a difusão, em termos de espaço (Kroeber, 1963, p. 139).

A definição pressupõe portanto a existência de um centro irradiador e de um espaço comum partilhado por culturas distintas. Por isso o difusionismo se interessa tanto pela comparação entre áreas de civilização e pela migração de traços culturais de uma determinada área para outra (aculturação e sincretismo). O argumento postula ainda uma clara distinção entre interno e externo, os elementos pertencentes a um "sistema-de-partida", fonte da irradiação, e os que se situam no "ponto-de-chegada". A difusão expressaria o momento de contato entre duas culturas, duas civilizações. Os lingüistas raciocinam de maneira análoga. O inglês é uma língua com uma história e centralidade própria que, por diferentes mecanis- mos (escolas, instituições, missões religiosas etc.), se difunde no mundo. No lugar de contato, quando encontra outros idiomas, produz-se a diglosia ou as assimilações. Isso significa, do ponto de vista do falante, que se trata de uma língua distinta da sua. A crítica feita pela visão anti-imperialista assenta-se nas mesmas premissas (Ortiz, 2002). A noção de imperialismo pressupõe a existência de um centro, a nação. Ela é o núcleo de um domínio que abarca o planeta, repartindo-o segundo o apetite inescrupuloso de poucos países industrializados. O imperialismo tem, pois, uma identidade, ele é inglês, norte-americano, alemão, francês, japonês. Cada foco de difusão procura propagar e impor, junto às nações periféricas, suas idéias, seus modos de vida. O que é externo à realidade nacional dos países periféricos pode ser então pensado como uma alienação, algo alheio, separado de sua "autenticidade" (recordo que o conceito de alienação foi decisivo no pensamento terceiro-mundista, tanto na América Latina, como na África - é o caso de Franz Fanon).

Entretanto, o fenômeno de globalização é distinto do de internacionalização. Nele as nações deixam de ser unidades autônomas, independentes, que se interagem entre si, para se constituírem em territórios atravessados pelo fluxo da modernidade-mundo. Nesse contexto, faz pouco sentido falar em centralidade difusora, ou numa nítida oposição entre externo e interno, estrangeiro e autóctone. Dizer que o inglês é uma língua internacional significa considerá-lo na sua integridade própria, circulando entre as nações. Uma outra coisa é nomeá-lo como língua global, isto é, um idioma que atravessa os distintos lugares do planeta. É significativo como os estudos sobre sua difusão o considerem um elemento "adicional", isto é, algo que se acrescenta a um suporte já existente. ${ }^{6}$ Daí a insistência no ensino de uma segunda língua. Por exemplo, quando um autor como Claude Truchot (1990) analisa a penetração do inglês entre os cientistas franceses nos anos de 1980, ele trata classicamente o tema em termos de diglosia. Haveria o contato de dois códigos distintos, um alto, outro baixo (evidentemente o baixo corresponde ao francês), no qual o falante utiliza, como estratégia comunicativa, um deles à dispo- 
sição. A predominância do inglês se faz como idioma das trocas científicas, ou seja, atua como língua internacional com maior capacidade de amplitude. Portanto, da perspectiva do cientista que o utiliza, ele é uma língua "estrangeira". Nada a criticar quanto a esse tipo de exposição, mas cabe sublinhar que ela resolve parcialmente o problema. Com o advento da globalização interessa saber se o inglês tem, apenas este atributo, ou deve ser compreendido de outra maneira, pois sua posição é inteiramente redefinida. Diria que no contexto da globalização o inglês deixa de ser estrangeiro, algo que se impõe de fora, para constituir-se num idioma interno, autóctone à condição da modernidade-mundo. Este é, a meu ver, o sentido da afirmação de David Crystal na abertura de seu livro English is the global langage (1997). Isso muda radicalmente as coisas.

Os lingüistas utilizam com freqüência a metáfora da ecologia, enfocando os idiomas como sistemas ecológicos. Uma primeira acepção do termo aproxima-se à idéia de natureza ameaçada; neste caso, tem-se a intenção de desenvolver alguns mecanismos de proteção das espécies, assegurando a condição de existência de determinas falas em situações adversas - por exemplo, o declínio do número de falantes conduziria à sua extinção. Esse interesse pela biodiversidade levou inclusive alguns autores a propor o desenvolvimento de uma política lingüística-ecológica, voltada para o multilingüismo, a manutenção das culturas e o respeito aos direitos humanos (Phillipson e Skutnabb-Kangas, 1996). Sei que essa perspectiva de trabalho é importante, e que a afirmação da igualdade dos direitos é fundamental na luta pelo ideal de uma "sociedade civil mundial” justa e equânime. No entanto, interessa-me na metáfora ecológica, no âmbito deste artigo, o fato de ela nos remeter à espacialidade das coisas. A ecologia, como meio ambiente, determina um entorno, uma territorialidade específica. Ora, sabermos que o processo de globalização implica uma radical transformação da noção de espaço, no qual categorias como difusão ou imperialismo se tornam inoperantes (cf. Ortiz, 1996). Como pensar então a configuração ecológica das línguas em relação a seus ambientes e aos outros idio- mas? Creio que a contribuição de Abram de Swaan (2001a) é relevante, uma vez que abre a possibilidade de se compreender a problemática em questão na sua estreita correlação com o movimento de globalização. ${ }^{7}$

Os indivíduos não têm sempre a possibilidade de escolher suas línguas, essa atribuição se faz no contexto topográfico em que vivem. Mas qual seria a cartografia do mundo globalizado? Swaan abandona a idéia bidimensional de planos - a localização dos idiomas no espaço de cada país ou de cada cultura - ao propor um desenho tridimensional sugerido pelo modelo da astronomia. O mapa lingüístico pode então ser pensado como uma galáxia, constituída por sóis, planetas, satélites, articulados a um mesmo sistema gravitacional. É possível, assim, distinguir constelações internas a este universo, o mundo. O bilingüismo dos indivíduos (mas não necessariamente da totalidade dos seres do planeta) teria a função de organizar a comunicação entre as diferentes peças que o compõem. A maioria das línguas, 98\%, estariam situadas na parte inferior desse universo, são os idiomas da memória, ágrafos, mas que contemplariam um número reduzido de falantes, 10\% dos habitantes da Terra. Línguas periféricas agrupar-se-iam em redor de uma língua central, podendo ser comparadas a luas gravitando em torno de um planeta. As línguas centrais, algo como uma centena - entre elas, quechua, bambara, tcheco, romeno etc. - em sua maioria, mas não exclusivamente, são idiomas nacionais, utilizados na imprensa, rádio, televisão, tribunais e burocracia estatal. Acima delas estariam as línguas supercentrais, cujo raio de ação é mais amplo, não se restringindo mais às fronteiras de um único país. Seriam os sóis em torno dos quais evoluiriam os planetas (línguas centrais) e os satélites (periféricas). Pertenceriam a esse grupo doze idiomas: árabe, chinês, inglês, francês, alemão, hindi, português, japonês, malaio, russo, espanhol, swalili. ${ }^{8}$ Cada um deles constituiria uma constelação, cabendo ao inglês o papel hiper-central, isto é, o nódulo nuclear dessa galáxia lingüística. O modelo apresentado ilustra como as trocas lingüísticas se fazem no interior de um mesmo conjunto. Nesse sentido, o inglês, como expressão de mundialida- 
de, transforma-se em parte estruturante de algo que o transcende. Sua origem, norte-americana ou britânica, torna-se secundária. Já não são mais as raízes de sua territorialidade anterior que contam, mas sua existência como idioma desterritorializado, apropriado, ressemantizado, nos diversos contextos de sua utilização. Fenômeno generalizado na esfera da cultura, na qual muitas das tradições nacionais e locais são redefinidas em termos de mundialização. É o caso do Pato Donald, das estrelas de Hollywood e do Western que perdem em americanidade, o mesmo acontece com Doreamon, Pokemon e a alta costura de Yamamoto em relação ao Japão, ou, ainda, a música pop em relação à Inglaterra. Da mesma maneira que eles passam a ser expressões de um imaginário coletivo mundial, a língua inglesa, ao se reterritorializar no espaço da modernidade-mundo, adquire um outro significado. Ao tornar-se mundial (diz-se global em inglês), ela se libera de seu enraizamento anterior, instituindo um artefato a ser legitimamente "deformado", "deturpado", pelos falantes de uma mesma galáxia.

Swaan considera ainda que toda linguagem é um "bem hiper-coletivo". Ela existe objetivamente disponível para os indivíduos (que para usá-las devem passar por um aprendizado) assim como os rios e os lagos fazem parte de nosso meio ambiente. Objetividade que lhe permite compará-la aos bens econômicos. As línguas podem então ser pensadas como padrões e redes de comunicação. Os padrões são convenções, protocolos para se operar uma máquina, procedimentos para coordenar determinadas ações; as redes são sistemas de conexões, como a rede elétrica com seus cabos ou a rede telefônica com seus sinais, capazes de articular um ponto do espaço à uma totalidade interconectada. Existem no mercado diferentes padrões técnicos para diversos tipos de redes em competição - PAL e Secam na televisão (daí a importância da escolha do padrão digital para o sistema televisivo de um país); ou ainda, os programas oferecidos pela Microsoft, que rodam apenas em alguns computadores. Para o indivíduo importa saber qual o tipo de benefício que irá obter, podendo, em várias ocasiões, trocar a assinatura do jornal, optar por um outro pacote de televisão à cabo etc. A lealdade lingüística é um caso extremo da lealdade do consumidor, pois o indivíduo não pode trocar facilmente de idioma. O argumento é interessante, mas dele é preciso retirar as conseqüências devidas. Dirá o autor:

[...] todas as vezes que as pessoas optam em utilizar um determinado padrão, subscrevem à uma rede particular de serviços, ou aprendem uma língua específica; ao fazer isso, elas incrementam a utilidade desse padrão, rede ou língua para todos os consumidores, associados ou falantes que já a utilizavam (Swaan, 2001a, p. 28).

Isso significa que a prática do inglês, seja como meio de comunicação, afirmação de prestígio, seja como expressão literária, implica o fortalecimento do padrão da língua inglesa no mercado de bens lingüísticos. Sua autoridade é reforçada quando as pessoas o empregam em suas tarefas cotidianas - do pós-colonialista que publica seu livro crítico em inglês, ao empresário brasileiro em suas viagens internacionais. Um exemplo expressivo dessa legitimidade ocorre no campo da música pop, em que é fartamente utilizado a despeito de ser ou não compreendido pelos jovens consumidores. Na verdade, a difusão em escala planetária de tal gênero musical independe da dificuldade de sua decodificação. Mas o que significa uma língua que não é entendida? Bourdieu em sua crítica ao estruturalismo lingüístico dizia que "escutar é crer" (1983). As forças simbólicas determinam os que falam e os que escutam, sendo que o princípio de autoridade é reforçado no momento em que a comunicação se completa. Paradoxalmente, encontramo-nos numa situação em que as pessoas apreciam o que não entendem. Elas escutam porque crêem. A legitimidade da língua é tal que ela prescinde do entendimento dos que a desconhecem.

$$
* * *
$$

O inglês é a língua da ciência. As razões para isso, além das apresentadas anteriormente, têm a ver com as profundas transformações que ocorreram no pós-Guerra. A ciência e a tecnologia, que até então evoluíam em esferas relativa- 
mente separadas de conhecimento, se integram num único sistema. Os historiadores ensinam-nos que a Revolução Industrial foi fruto muito mais das invenções pragmáticas de alguns indivíduos, do que o resultado de um conhecimento científico amplo e sistemático. O panorama no final do século XIX transforma-se com a segunda revolução industrial. A indústria elétrica é conseqüência direta das investigações científicas, assim como as invenções do telégrafo, do dínamo, do motor elétrico e do rádio. Mas não se pode ainda observar o inverso, ou seja, uma clara e persistente influência das pesquisas tecnológicas no funcionamento do universo científico. Essa tendência impõe-se ao longo do século XX, e a expressão "tecnociência” revela bem sua nova dimensão. As tecnologias pressupõem um investimento contínuo de capital, a formação de quadros especializados e a constituição de laboratórios de pesquisa. No início, isso se concentra nos Estados Unidos, pois quando termina a Segunda Guerra Mundial, tratase do único país industrializado onde a infra-estrutura educacional e tecnológica permanece intacta. Com a expansão do ensino superior e o desenvolvimento dos institutos de pesquisa, assiste-se a um florescimento científico sem precedentes, aliado a uma política tecnológica na qual as criações científicas estão vinculadas às descobertas e ao aperfeiçoamento das técnicas. A história do computador é um bom exemplo do imbricamento das dimensões econômica, militar e científica num mesmo projeto. Como processador de dados e informações, irá impulsionar todo um campo de atividades, desde as experiências de laboratório até a administração das empresas (cujo raio de ação é, muitas vezes, transnacional). Ciência, tecnologia e administração - esferas diferenciadas de práticas e saberes - aproximam-se assim como unidades que se alimentam e se reproduzem a partir da manipulação, do controle e do processamento da informação. Creio que não seria exagero dizer que os elementos-chave do que entendemos por sociedade de informação foram inicialmente preparado em inglês (conceitos, modelos, fórmulas e procedimentos).

Não é difícil seguir o advento e o itinerário desta supremacia. Uma maneira de entendê-la é olharmos para as mudanças nos currículos das escolas secundárias em relação ao ensino das línguas estrangeiras. Yun-Kyung Cha, utilizando uma série de dados estatísticos, referentes a todos os países do mundo, apresenta alguns elementos interessantes para a reflexão (os dados devem ser tomados com precaução, particularmente no caso de análises abrangentes como essa, mas creio que eles sejam eloqüentes) (Cha, 1991, p. 29). Em meados do século XIX (1850-1870) os idiomas francês e alemão, em conjunto, eram ensinados em 91\% das escolas secundárias existentes (45,5\%, respectivamente) e o inglês, em 8,3\% delas. Entre 1900-1944 esses números foram alterados (inglês, 39,6\%; francês, 47,9\% e alemão, 16,3\%), mostrando um razoável equilíbrio entre os idiomas. Entre 1972-1986 alterou-se definitivamente esse quadro: inglês (72\%), francês $(17,6 \%)$ e alemão $(0,8 \%)$. Considerando que a escola secundária é um fator importante no aprendizado de uma língua estrangeira, condição decisiva no mundo das ciências, pode-se inferir a que ponto chegou a transformação do padrão de ensino. Uma outra maneira de abordar a questão é observar o crescimento exponencial dos artigos publicados em inglês em algumas áreas científicas (Tsunoda, 1983). Em matemática, o Bulletin signalétique mostra que, entre 1940 e 1980, o número de textos em inglês passou de $49,5 \%$ para $71 \%$, enquanto o francês caiu de $31,2 \%$ para $6,1 \%$, e o alemão de $13,2 \%$ para 1,6\%. O Berichte Uber die Gesamte Biologie indica que as publicações em inglês passaram, entre 1926 e 1980, de 26,7\% para 55,9\%, enquanto em francês diminuíram de $16,4 \%$ para $1 \%$, e em alemão de $50 \%$ para $42,1 \%$. Nas revistas de origem norte-americana a desproporção é mais acentuada: Physics Abstracts mostra que entre 1950 e 1980 os textos em inglês aumentaram de 70,3\% para $88,6 \%$, sendo as publicações em outras línguas quase insignificantes. Alguns lingüistas, entre eles Richard Baldauf, elaboraram séries históricas que nos permitem ter uma visão mais nítida das diferentes áreas de conhecimento. Entre 1965 e 1988, os artigos publicados em inglês na área de biologia passam de $50 \%$ para $75 \%$; em engenharia, de $82 \%$ para $86 \%$; em medicina, de $51 \%$ para $75 \%$; e em matemática, de $54 \%$ para $82 \%$. Tendência que 
se acentua com o passar dos anos em todas as especialidades. Mas não são apenas os artigos que confirmam esse movimento, as citações, ou melhor, as obras de referências o reforçam integralmente. Um estudo realizado sobre as revistas de geologia mais significativas da área ilustra bem esse aspecto (Reguant e Casadellà, 1994). Em periódicos como American Association of Petroleum Geologist Bulletin (Estados Unidos) e Journal of the Geological Society (Reino Unido) as referências a trabalhos escritos em inglês são praticamente exclusivas (95,5\% e 91,6\% respectivamente). Predominam, ainda, nas publicações de outros países: Geologische Rundschau, 64,4\%; Estudios Geologicos, 40,3\%; Rivista Italiana di Paleontologia e Stratigrafia, 48,3\%; Engineering Geology (Países Baixos), 90,2\%. Fecha-se assim um circuito: os artigos passam a ser escritos e citados preferencialmente em inglês.

Não se deve imaginar das estatísticas apresentadas que toda a produção científica, ou mesmo a sua maioria, se faça em inglês. Embora não existam dados disponíveis em escala mundial, pode-se argumentar, e com boa parte de razão, que a literatura científica em língua não inglesa tenha aumentado. Basta ver a proliferação de revistas nos mais diferentes países e a participação dos cientistas em reuniões e congressos especializados. No entanto, como sublinha Baldauf, sua representação na literatura recenseada nas principais bases de dados declinou. As bases de dados, apesar de serem consideradas por muitos como representativas da produção científica, na verdade formam uma projeção distorcida do que realmente acontece. Grande parte do que é produzido é simplesmente ignorado pelo fato de não estar formalizado e formatado em informação imediatamente disponível, ou seja, compreensível para um conjunto amplo de pessoas. Existe ainda uma seleção entre as publicações, daí a disputa surda, entre os cientistas, a respeito da fidelidade ou não do Science citation index. Entretanto, importa entender que um corpus literário, funcionando como padrão de referência, é legitimado mundialmente somente quando disponível em inglês. Daí a estratégia de vários grupos, particularmente no "Terceiro Mundo", de dividir suas atividades em "locais" e "universais". As primeiras são escritas em idioma nacional e têm como veículo as revistas existentes no país; as outras concentram os cientistas de "elite", cuja ambição é conseguir uma maior visibilidade na cena mundial; interessa-lhes publicar nas revistas internacionais já consagradas. Nesse caso, tanto a elaboração de artigos, como de papers tendem a reter o inglês como língua franca (Russell, 1998). Uma outra estratégia é editar revistas inteiramente em inglês ou publicar, nas revistas nacionais, um número significativo de textos nesse idioma. Isso acontece em diversas publicações especializadas: Anales de la Asociación Química Argentina (53\% dos textos em inglês), Biocell (Argentina, 100\%); Brazilian Journal of Genetics (100\%), Computation and Applied Mathematics (Brasil, 100\%), Arquivos de Neuro-Psiquiatria (35\%); Archives of Medical Research (Mexico, 100\%); Revista de Biologia Tropical (Costa Rica, 41\%). ${ }^{10}$

A expressão "língua franca" é recorrente. Encontra-se geralmente associado ao latim, idioma que outrora foi considerado a língua do saber. Essa imagem pode ser verdadeira, mas encobre aspectos não confessados. Há primeiro uma incongruência, ou seja, a aplicação de um conceito estranho às categorias de uma determinada época. Na Idade Média, por exemplo, scientia equivalia a "um saber certo", e aplicava-se apenas à teologia, à lógica, à física e à matemática (Blair, 1996); a astronomia e a ótica, por sua vez, eram chamadas de ciências médias, pois emprestavam seus princípios a outras disciplinas; navegação, contabilidade, cirurgia, farmácia e construção de edifícios eram especialidades práticas, ou melhor, artes. O latim era a língua da scientia, enquanto os outros saberes, dos médios às artes, exprimiam-se em vernáculo. Em segundo lugar, na hierarquia prevalente, servir-se da língua vulgar equivalia à desclassificação ou rebaixamento, isto é, o latim não era apenas uma língua franca, mas um meio prestigioso de comunicação. A rigor, deveríamos dizer, nenhuma língua "é" franca, ela apenas desempenha, em determinados domínios, a "função de ser" franca. Nesse sentido o inglês, no universo das ciências da natureza, atua como um idioma predominantemente "franco", seu papel con- 
centra-se na informação transmitida, minimizando outras dimensões da vida em sociedade (prestígio, estética, sentimentos etc.). Mas se isso é possível, e este é o elemento valorizado pelos cientistas - utiliza-se nos congressos uma língua esvaziada de outras conotações com o intuito de maximizar a comunicação instrumental -, o que dizer das ciências sociais?

Retomo de Barthes uma observação que faz ao comparar literatura e ciência. Ele diz:

[...] Para a ciência, a linguagem é apenas um instrumento, aprisionado à matéria científica (operações, hipóteses, resultados) que se diz, a antecede existe fora dela, e que se tem o interesse de torná-la o mais transparente e neutra possível: há, de um lado, num primeiro plano, o conteúdo da mensagem científica, que é tudo; de outro, num segundo plano, a forma verbal, que exprime esse conteúdo e que é nada [...]. Para a literatura [...] a linguagem é o seu ser, seu mundo: toda a literatura está contida no ato de escrever [...]. A ciência tem certamente necessidade da linguagem, mas ela não está, como a literatura, na linguagem (Barthes, 1984b, pp. 14-15).

É preciso ter em mente que a qualidade de ser instrumental não deve ser vista como algo negativo, no sentido frankfurtiano de razão instrumental, ou, falando em literatura, de um empobrecimento da linguagem (embora Barthes às vezes tenha essa intenção). Trata-se de uma opção deliberada em utilizar a linguagem como uma ferramenta, cujo resultado é altamente compensador - o discurso científico. Resulta disso o amplo consenso (embora sem unanimidade) existente entre os cientistas em relação ao uso do inglês, qual seja, o fato de ele ser instrumental e eficiente. ${ }^{11}$ Mas qual seria a razão dessa instrumentalidade? Richard Harris e Paul Mattick, trabalhando com as propriedades da linguagem e sua relação com a informação, têm um argumento interessante. Consideram que cada domínio científico utiliza a linguagem de maneira limitada, por isso é mais fácil traduzir textos científicos do que literários. Isso significa que a informação provida na mensagem é dada não apenas pelo significado individual das palavras, mas também pela relação entre elas, sua co-ocorrência e combinação. Por exemplo, podemos enunciar as sentenças "para mim é preferível sair por último" e "eu prefiro sair por último"; há aí uma variação da forma mas não da informação transmitida. O caso é distinto no discurso científico, no qual ocorre uma forte restrição na co-ocorrência das palavras. Em bioquímica pode-se dizer "os polypeptides foram lavados em ácido hidroclorídrico", mas "ácido hidroclorídrico foi lavado em polypeptides", embora gramaticalmente correto, seria uma afirmação implausível. Ao analisar a co-ocorrência das palavras no discurso científico, torna-se então possível definir campos de sublínguas separados do idioma utilizado. Afirmam os autores:

\begin{abstract}
Examinando-se a estrutura das sublínguas da bioquímica em francês e em inglês - isto é, os subgrupos de nomes, verbos e outros elementos de sentenças deles compostos - verifica-se que elas são idênticas. Ao marcar os diversos subgrupos de palavras da sublíngua em inglês com letras - por exemplo, P para polypeptides e outras moléculas que possam ser tratadas por lavagem, W para certas operações de laboratório, e S para certas soluções -, poderíamos representar tipos de sentenças por seqüências dessas palavras-símbolos. Tal sentença seria, "PWS". É possível demonstrar que a mesma classe de símbolos e seqüências de sentenças de símbolos são suficientes para caracterizar as classes de palavras e os tipos de sentenças da sublíngua da bioquímica em francês. Isso significa que artigos em qualquer língua, num determinado campo da bioquímica, poderia ser representado por seqüências do mesmo tipo de fórmula (Harris e Mattick, 1988, p. 76).
\end{abstract}

Dentro da perspectiva da lógica e da lingüística, eles estão procurando uma possível gramática da ciência, o que certamente é complexo. Importa, porém, para nossa discussão, que o raciocínio apresentado para justificar a existência de sublínguas nas ciências revela muito de sua natureza discursiva. Ao fixar as sentenças em posições determinadas pode-se representar a informação, liberada dos aspectos não informacionais da linguagem. Esse processo de redução, que Barthes considera "transparente" e "neutro", somente é possível quando a informação é o interesse central na transmissão. O discurso deve se desnudar 
ao máximo de suas características externas para exprimi-la da melhor maneira possível.

As ciências sociais estão demasiadamente amarradas aos contextos, daí a dificuldade de universalização de seus discursos. A crítica de Jean Claude Passeron (1995) ao idealismo científico do tipo popperiano é sugestiva e ajuda o encaminhamento do debate. O autor lembra que a pesquisa sociológica procede por veredas teóricas que sempre recomeçam porque nunca estão definitivamente separadas da "literalidade" dos enunciados que lhe conferem sentido. Não é possível, portanto, partir de uma teoria geral, uma série abstrata de conceitos, e ser capaz de deduzir o que se encontraria na realidade. Por isso o método comparativo - a capacidade de estabelecer relações - é fundamental; o cientista social não possui um laboratório para fazer experiência, a própria noção de experiência, tal como se dá nas ciências naturais, lhe escapa. O caminho da abstração requer, então, um esforço comparativo ou relacional constante. Ademais, o objeto das ciências sociais está em permanente mutação, ele é também histórico. Nesse sentido, a prática sociológica é sempre uma estenografia, ou uma taquigrafia, como prefere nomeá-la Octávio Ianni (1997). Essa imagem é sugestiva. Taquigrafia e estenografia são linguagens abreviadas; da riqueza da língua, retêm apenas alguns traços. As notações taquigráficas contêm um grau de abstração que não está contido na amplitude da língua; por serem mais simples, ganham em universalização. Porém, essa universalização nunca é inteira, emancipada, pois as notações se encontram aprisionadas à "literalidade dos enunciados". O pensamento sociológico é sempre uma tradução, algo intermediário entre o ideal de universalidade (que é necessário) e o enraizamento dos fenômenos sociais. Ora, contexto e língua conjugam-se mutuamente. O discurso das ciências da natureza se justifica porque consegue reduzir a linguagem, depurá-la de sua malha sociocultural, algo impensável quando se deseja compreender a sociedade. Nesse caso, o inglês não pode funcionar como língua franca, não por uma questão de princípio, ou de orgulho nacional, mas devido à própria natureza do saber construído.
Diversos obstáculos podem ser sublinhados. O problema da tradução, por exemplo. ${ }^{12}$ A passagem de um idioma para outro, longe de ser imediata, como se ambos pertencessem a uma mesma sublíngua, é necessária (o pensamento e as obras devem circular, este é um imperativo para todo conhecimento), mas custosa. É preciso sempre um esforço adicional de interpretação, pois nenhuma tradução é literal. Termos, conceitos e abstrações devem buscar equivalentes quando passam de um código para outro. A língua reforça o vínculo discursivo ao solo onde as ciências sociais são elaboradas. Mas não se trata apenas de tradução direta, existem diferentes tradições, e muitas vezes vertêlas de uma língua para outra não significa simplesmente encontrar o vocábulo adequado, mas considerar toda uma constelação expressiva. Quando se diz, por exemplo, "questão nacional" ou "cuestion nacional", a oração dificilmente poderia ser reduzida a "nationalism". "Questão nacional" implica um pano de fundo no qual se desenrola todo um debate intelectual na América Latina, discussão que se faz do final do século XIX ao final do XX, envolvendo pensadores, artistas e políticos. Refere-se à problemática da identidade nacional, da construção da nação e da modernidade; nela está incluída a crítica à importação de idéias, o complexo de inferioridade dos países colonizados, assim como os dilemas da modernidade periférica. "Nacionalismo" é uma das facetas de uma problemática bem mais ampla. "Questão nacional" diz respeito ainda a toda uma tradição bibliográfica, de Vasconcelos no México à Gilberto Freyre no Brasil, do desenvolvimentismo da Cepal à teoria da dependência. Mesmo a equivalência do termo em francês - "question nationale" -,é dúbia, pois trata-se de constelações de significados distintos. Na verdade, na própria literatura escrita em Portugal (o termo remete à descolonização da África), ou na Espanha (ao debate sobre o iberismo), o sentido é inteiramente diverso. "Questão nacional" é uma expressão taquigráfica vinculada à história dos países latino-americanos, periféricos, em busca de suas identidades.

Barthes dizia que a linguagem era para a literatura o seu ser, e que ela consistia e se concentrava no ato de escrever. Certamente não poderíamos dizer que a linguagem é o "ser" das ciências 
sociais; existem técnicas de pesquisa, metodologias, teorias, enfim, obrigações que a distanciam da literatura. Mas a escrita é um elemento comum às duas tradições. Os cientistas sociais têm razão quando insistem na importância das regras metodológicas no entendimento da sociedade, mas às vezes se esquecem de acrescentar o fato de elas se realizarem no texto. A escrita é o suporte e a concretização do recorte conceitual. As mesmas informações, os mesmos dados, podem ser costurados de maneira distinta por autores diversos. Não há objeto fora do texto, seu conteúdo, para existir, deve ser formalizado. Uma grande parte da exposição argumentativa é uma questão de composição. As informações primárias são previamente apreciadas, filtradas, antes de figurarem na página em branco ou na tela do computador. A composição é crucial para o trabalho intelectual. Nesse sentido, a construção do objeto sociológico se faz por meio da língua, portanto a utilização de um determinado idioma não é algo fortuito, mera sutileza de estilo, mas uma questão decisiva na formulação final. Retiro um exemplo de minha própria pesquisa, quando propus, faz algum tempo, uma distinção conceitual entre "mundialização" e "globalização". Quando falamos de economia e de tecnologia nos referimos a processos que se reproduzem igualmente em todo o mundo. Há apenas uma economia global, o capitalismo, e um único sistema técnico (computadores, Internet, satélites etc.). Global remete-nos, assim, à idéia de unicidade. Seria entretanto inadequado sustentar essa mesma idéia quando se entra da esfera da cultura. Não há uma cultura global, mas um processo de mundialização da cultura, o qual se exprime em dois níveis: a) articulada às transformações econômicas e tecnológicas da globalização, a modernidade-mundo é sua base material; b) espaço de diferentes concepções de mundo, no qual formas diversas e conflituosas de entendimento convivem. Por isso prefiro dizer que o inglês é uma língua mundial e não global, pois preservo, na afirmação, a diferença entre a diversidade da esfera cultural diante da unicidade dos domínios econômico e tecnológico. Sua mundialidade se dá no interior de um universo transglóssico habitado por outros idiomas. O leitor pode aceitar ou não minha proposição, considerá-la re- levante ou insuficiente, mas somente pude elaborá-la porque a língua portuguesa possui dois termos distintos, que podiam ser investidos de conteúdos diferenciados. Caso escrevesse em inglês seria obrigado a me contentar com globalization, global culture, global language.

O contraste entre ciências sociais e naturais pode ser ainda melhor trabalhado. Diversos estudos mostram que nessas últimas as revistas são consideradas documentos "primários", veículo das "informações de primeira mão". ${ }^{13}$ A revista é o meio por excelência da ciência em andamento; situa-se na fronteira, na brecha que se instala entre o que se sabe e o que está para ser conhecido. Os pesquisadores e as equipes de laboratório a privilegiam em contraposição ao livro, considerado um manual informativo, suporte secundário na elaboração de novas teorias e descobertas. As publicações tendem, assim, a valorizar os resultados recentes, que trazem dividendos para o conjunto da área, daí a insistência de muitas das revistas, sobretudo as mais bem qualificadas na classificação mundial, em exigir artigos cujos resultados não foram ainda publicados. A premência do tempo é tal, que vários grupos de cientistas, principalmente os físicos, lançam mão de uma outra estratégia: a pré-tiragem. O pesquisador, ou o grupo de pesquisadores, uma vez terminado um artigo, o submete à aprovação da alguma revista e, simultaneamente, o edita em sua instituição, distribuindo-o por correio eletrônico. Informação e tempo são portanto elementos fundamentais que favorecem o uso do inglês. É necessário se exprimir de forma mais abrangente, numa duração a mais curta possível. Em contrapartida, para as ciências sociais o livro é o suporte privilegiado; mesmo os artigos são longos, ao contrário dos textos curtos (às vezes curtíssimos) das ciências naturais. Não se trata meramente de uma questão de prestígio (ele existe nas "humanas" e nas "exatas"), mas aqui a idéia de informação possui uma outra relevância. Ela é parte integrante de um conjunto teórico e explicativo, sendo que, muitas vezes, esse arcabouço interpretativo é mais importante do que os dados veiculados (o que não significa dizer que a informação seja irrelevante). As ciências sociais são mais interpretativas do que informativas, requerem tempo de amadurecimen- 
to e análise. Não há portanto a premência de se publicar imediatamente os resultados de pesquisa, e se porventura eles forem difundidos em outra língua, é necessário esperar pelo tempo da tradução. O ritmo desse processo marca inclusive o tipo de material utilizado e valorizado pelo cientista social. Nas ciências da natureza, a corrida para expandir a fronteira do conhecimento faz com que as descobertas muito rapidamente tornem obsoletas as certezas do passado. A informação recente, atual, tem assim um valor insubstituível. Nas ciências sociais a vigência dos materiais utilizados nas pesquisas recuam às vezes séculos quando se trata, por exemplo, da leitura dos clássicos. Alguns estudos sobre a prática dos cientistas sociais a respeito da utilização dos dados bibliográficos mostram que em todos os lugares tanto o material consultado, como as citações cobrem períodos bastante longos, ou seja, nessa esfera do conhecimento textos e informações envelhecem vagarosamente. ${ }^{14}$

Não obstante, apesar dessas diferenças marcantes, a presença e a supremacia do inglês são patentes. Um estudo sobre a relação entre os idiomas e as áreas disciplinares, realizado entre 1981 e 1985, com a base de dados International Bibliography of the Social Sciences, compilada pelo International Committee for Social Science Information and Documentation, apresenta os seguintes resultados: em antropologia - inglês, 55,5\%; francês, 14,4\%; espanhol, 7,7\%; russo, 7,2\%; alemão, 6,3\% -; em ciência política - inglês, 50,1\%; francês, 16,5\%; alemão, 7,9\%; russo, 7\%; espanhol, $6,3 \%$-; em sociologia - inglês, 49,7\%; francês, 17,6\%; alemão, 7,5\%; russo, 6,1\%; espanhol, 5\% -; e em economia - inglês, 55\%; francês, 13\%; alemão, 7,5\%; russo, 6,1\%; espanhol 5\% (Kishida e Matsui, 1997). Certamente o predomínio de um idioma depende muito da maneira como são confeccionadas as bases de dados. Outro trabalho, de 1991, comparando duas delas, uma da Unesco (World List of Social Science Periodicals), outra o Social Sciences Citation Index (SSCI), traz informações sugestivas. Na base de dados da Unesco, $64 \%$ de revistas compiladas pertencem ao grupo de países com alta renda, 22\% com renda média (inclui a maioria dos países latino-americanos) e $14 \%$ com baixa renda. No SSCI, os países de bai- xa renda são representados com apenas 0,7\% de suas revistas, os de renda média com 2,3\% e os de alta renda com 97\%. Com exceção dos Estados Unidos, há uma diminuição significativa do número de revistas dos outros países: Brasil (passa de 81 na base Unesco para 3 no SSCI); França (de 295 para 23); Alemanha (de 217 para 51); México (de 47 para 2). A presença do inglês na base Unesco, somado apenas Estados Unidos e GrãBretanha, representa $32 \%$ da amostra total; na SSCI, esse número sobe para 79\% (Narvaez-Berthelemot e Russel, 2001). O problema é que as bases de dados não armazenam apenas informações, tornando-se também artefatos de prestígio. Algumas têm mais legitimidade do que outras. Este é o ponto central. O inglês, em sua presença quantitativa, se insinua pouco a pouco como uma hegemonia qualitativa. Isso fica claro quando se analisa a diferença entre a freqüência dos textos publicados em inglês e as citações às obras elaboradas em inglês. A partir da fonte do SSCI, entre 1990 e 1992, Glänzel (1996) discriminou as publicações segundo os países de origem, distinguindo, ainda, os artigos nacionais e os internacionais (colaboração de pelo menos dois pesquisadores de países diferentes). O resultado é expressivo. A França, sub-representada na amostragem inicial, comparece com 2,9\% de artigos nacionais e 9,4\% internacionais, mas sua cota de citação atinge apenas 0,8\%. Há, pois, uma drástica diminuição em relação ao total de artigos publicados. Os Estados Unidos, com 56,9\% de textos em revistas nacionais e $6 \%$ em internacionais (um número inferior ao da França), vêem sua representação fortemente valorizada, pois sua cota em citações sobe para $76 \%$. Por outro lado, Grã Bretanha, Austrália e Canadá, países de língua majoritária inglesa, mantêm um equilíbrio entre o conjunto de textos publicados e as referências. Esses mesmos resultados são confirmados quando se analisa algumas revistas norte-americanas e britânicas: American Sociological Review (98,6\%), Sociology (98,8\%), The Sociological Review (99,3\%), British Journal of Sociology (99,5\%) e Theory Culture and Society (89,6\%) (cf. Yitzhaki, 1998).

Se o inglês não funciona como língua franca nas ciências sociais, qual seriam o significado e a implicação de sua presença dominante? Minha im- 
pressão é de que, por sua abrangência, esse idioma adquire a capacidade de "pautar" o debate em escala global. Em jornalismo, "pautar" significa selecionar, entre tantos, alguns problemas existentes, tornando-os relevantes e visíveis. Esse tipo de procedimento favorece a existência de um conjunto hegemônico de representações mundializadas, que passam a ser aceitas como válidas, naturalizando procedimentos metodológicos e diversas problemáticas. Por exemplo, os "estudos culturais", ou o "multiculturalismo", deixam de ser pensados em relação ao contexto em que foram gestados, e no qual fazem sentido, para se imporem como "universais". Bourdieu e Wacquant no texto "On the cunning of imperialist reason" (1999) vão contra essa perspectiva. ${ }^{15}$ Apesar de o argumento central do artigo ser, a meu ver, equivocado, já que os autores retomam sem uma visão crítica a noção de imperialismo, e têm uma compreensão estreita do processo de globalização (para eles, sinônimo de americanização), o que está em discussão é justamente a questão da "falsa universalização". Ou seja, como certas idéias e visões de mundo se difundem e se legitimam entre as diferentes sociedades sem que haja uma prévia reflexão crítica a seu respeito. Isso só é possível porque no debate sobre a globalização há uma tendência em pensá-la como equivalente à universalização. O que torna essa equivalência crível é a idéia de territorialidade. Ao expandir suas fronteiras, ao desterritorializar-se, o universal e o global participariam de um mesmo movimento, transcendendo as diferenças locais. Assim, quando alguns sociólogos discutem a relação universalismo versus particularismo, penso em Robert Robertson, o termo global surge como um atributo intrínseco ao universalismo, restando ao particularismo uma expressão reduzida, territorialmente localizada.

Não resta dúvida de que as ciências sociais vêm se transformando com o processo de globalização. As mudanças nas relações sociais requerem um novo olhar e a definição de novas categorias de pensamento. Certamente, ao tomar o mundo como tema de reflexão, o estudioso liberta-se do espaço circunscrito pela territorialidade das regiões ou do Estado-nação. Mas seria incorreto imaginar que as análises sociológicas teriam se tornado, atualmente, "mais universais" do que no passado. O estatuto da explicação sociológica, como o qualificava Passeron, permanece inalterado. Também os economistas insistem em dizer que o capitalismo global contribui para a universalização dos espíritos; já a literatura que se ocupa de maketing e business não hesita em afirmar que os indivíduos consomem produtos globais porque eles atendem a seus desejos universais. Essa aproximação indevida entre global e universal deriva da utilização recorrente da metáfora espacial. Ou seja, tudo se resumiria a uma expansão dos limites espaciais. No entanto, "universal" é uma categoria filosófica, e "global", uma categoria sociológica. A primeira significa transcendência, trata-se de uma relação abstrata que não se realiza necessariamente de maneira imediata - é isso que permite aos iluministas falarem em "gênero humano". Quando nomeamos mercado global, sociologia global, economia global, identificamos coisas e processos que se desenvolvem no plano da história real dos homens. Assim, ao aproximar conceitos tão distintos, sugere-se que o universal se realiza no global, o que é evidentemente falso. O idioma inglês participa dessa ilusão coletiva, e novamente o contraponto com as ciências da natureza é elucidativo. A possibilidade de ele se transformar numa língua franca decorre também do fato de as ciências naturais serem paradigmáticas, no sentido dado por Khun. Elas pressupõem um único sistema de referência em relação ao qual as práticas científicas se organizam. Características como estas - comunalidade e abrangência - permitem associá-las à idéia de universalidade; suas leis, descobertas e explicações são igualmente válidas. Contudo, as ciências sociais não são paradigmáticas nesse sentido. No limite, se pensarmos em termos do contexto, deveríamos dizer que o ideal seria o conhecimento de todas as línguas nas quais as ciências sociais se exprimem, para se obter, não uma universalização do espírito, mas uma biblioteca de idiomas a serviço de uma maior riqueza do pensamento. Embora isso seja irrealizável, é importante tê-lo em mente, pois o cosmopolitismo das idéias somente pode existir quando levamos em consideração a diversidade dos contextos e os "sotaques" das tradições sociológicas. Entretanto, o que se observa é um movi- 
mento na direção contrária a qualquer tipo de diversidade das interpretações. O mercado mundial das traduções nos dá uma boa imagem desse fato. Nos Estados Unidos e no Reino Unido menos de 5\% das obras publicadas são traduções (incluindo obras literárias); na França e na Alemanha esse número gira em torno de $12 \%$, sendo que na Espanha e na Itália chega a 20\% (cf. Heilbron, 1999). Isso significa que quanto mais central é um idioma no mercado mundial de bens lingüísticos, menor é a proporção de textos nele traduzidos. O corolário desse axioma é que as traduções entre línguas periféricas se tornam cada vez mais raras, pois devem passar necessariamente pelo vernáculo mundial. Na verdade, quando assistimos à expansão das bases de dados, à constituição de bancos de informações, à publicação de livros e artigos, o aumento das citações de obras escritas em inglês, e com advento das revistas on-line, tudo isso, conjugado prioritariamente em inglês, tem-se a falsa impressão de que tal abrangência é sinônimo de universalidade. Publicar e ser citado em inglês não seria, pois, o resultado da expansão de um circuito, de sua amplificação territorial, mas a condição primeira do pensamento (daí os autores anglo-americanos se ajustarem tão bem ao monolingüismo, afinal, fora dele, pouca relevância científica existiria). Escrever em outra língua deixa também de significar, estar circunscrito a uma determinada forma de expressão, essa condição é percebida como uma limitação. Isso fica claro quando se extrapola certos julgamentos da área das ciências da natureza para as ciências sociais. A estratégia de grupos de elite das áreas de física, química e biologia de países de língua não inglesa de escrever e publicar em inglês implica a idéia de que existe um desnível hierárquico entre o local e o universal. Daí a tendência em se afirmar que as revistas editadas em língua nacional estão voltadas para aspectos locais, cuja importância para o desenvolvimento do saber científico seria menor. Pode-se discutir a validade dessa hierarquia, mas ela se assenta na existência de paradigmas aceitos pela comunidade científica internacional. No caso das ciências sociais isso não ocorre, mas mesmo assim o paralelismo é implicitamente aceito. Global english torna-se universal english. Temos, assim, não apenas uma hierarquia entre os idiomas, marcando a desigualdade existente entre eles, mas um elemento sutil de segregação intelectual se instaura. A homologia postulada entre local-global/particular-universal fecha o círculo, rebaixando as outras interpretações à posição subalterna de localismo. Convenientemente se esquece que o cosmopolitismo não é um atributo necessário da globalidade e que o particularismo do pensamento se enuncia tanto em dialeto como em linguagem global, pois na condição da modernidade-mundo é plausível, e corriqueiro, ser globalmente provinciano.

\section{NOTAS}

1 Fishman, Cooper e Conrad (1977), Bailey e Görlach (1982), Cooper (1982) e Greenbaum (1985).

2 Cito, entre outros, McArthur (1987).

3 Remeto o leitor ao texto clássico de Ballandier (1951), quando o autor, ao criticar a perspectiva culturalista, cunha o conceito de "situação colonial".

4 Existem exceções que confirmam a regra, por exemplo, o artigo de Swaan (1991).

5 Retomo a argumentação desenvolvida em meu livro Mundialização e cultura (1994).

6 Como sugere o título do artigo de Fishman (1982), "English as an additional language".

7 Uma perspectiva próxima à sua foi trabalhada por Calvet (1999).

8 Há uma controvérsia em relação ao número dessas línguas. Calvet contesta ao japonês e ao alemão a posição atribuída por Swaan; para ele, seriam idiomas com um número grande de falantes, mas concentrados num mesmo espaço geográfico.

9 Ver os dados em Baldauf Jr. (2001).

10 Ver dados em Gómes, Sancho, Moreno e Fernández (1999).

11 Ver, entre outros, Alberch (1996).

12 Swaan (2001b) chama a atenção para esse aspecto.

13 Ver, entre outros, Josette de la Veja (2000).

14 Ver, entre outros, Stone (1982) e Romanos de Tiratel (2000). 
15 Para uma crítica interessante ao ponto de vista dos autores, ver Friedman (2000).

\section{BIBLIOGRAFIA}

ALBERCH, Pere. (1996), "Language in contemporary science: the tool and the cultural icon", in R. Chartier e P. Corsi (orgs.), Sciences et langues en Europe, Paris, Centre Alexandre Koyré.

AMMON, Ulrich (org.). (2001), The dominance of english as a language of science. Berlim/Nova York, Mouton de Gruyter.

BAILEY, Richard \& GORLACH, Manfred (eds.). (1982), English as a world-language. Ann Arbor, The University of Michigan Press.

BALDAUF JR., Richard. (2001), "Speaking of science", in Ulrich Ammon (org.), The dominance of english as language of science, Berlim/Nova York, Mouton de Gruyter.

BALLANDIER, Georges. (1951), "La situation coloniale: approche théorique". Cabiers Internationaux de Sociologie, XI.

BARTHES, Roland. (1984a), Le bruissement de la langue. Paris, Seuil.

(1984b), "De la science à la littérature", in Le bruissement de la langue, Paris, Seuil.

BLAIR, Ann. (1996), "La persistence du latin comme langue de science à la fin de la Renaissance", in R. Chartier e P. Corsi (orgs.), Sciences et langues en Europe, Paris, Centre Alexandre Koyré.

BOLTON, W. F. \& CRYSTAL, David (eds.). (1987), The english language. Nova York, Peter Bedrick Books.

BOURDIEU, Pierre. (1982), Ce que parler veut dire. Paris, Fayard.

(1983), "O mercado de bens lingüísticos", in R. Ortiz, Pierre Bourdieu, São Paulo, Ática.
BOURDIEU, P. \& WACQUANT, L. (1999), "On the cunning of imperialist reason". Theory Culture and Society, 16 (1).

BRETON, Pierre. (1991), História da informática. São Paulo, Editora da Unesp.

CALVET, Louis Jean. (1999), Pour une écologie des langues du monde. Paris, Plon.

(2002), Le marché aux langues: les effets linguistiques de la mondialisation. Paris, Plon.

CHA, Yun-Kyung. (1991), "Effect of the global system on language instruction, 18501986". Sociology of Education, 64, jan.

CHARTIER, R. \& CORSI, P. (orgs.). (1996), Sciences et langues en Europe. Paris, Centre Alexandre Koyré.

CRYSTAL, David. (1997), English as a global language. Cambridge, Cambridge University Press.

COOPER, R. (org.). (1982), Language spread. Bloomington, Indiana University Press.

DURAND, Jacques. (1996), "Linguist purification, the French Nation-state and the linguist", in Charlotte Hoffmann, Language, culture and communincation in contemporary Europe, Clevedon (Philadelphia), Multilingual Matters Ltd.

FERREIRA, Leila (org.). (1997), A sociologia no século XXI. São Paulo, Boitempo.

FISHMAN, Joshua. (1982), "English as an additional language", in Braj Kachru (org.), The other tongue, Chicago, University of IIlinois Press.

FISHMAN, J.; COOPER, R. \& CONRAD, A. (orgs.). (1977), The spread of the english, Rowley (Massachusetts), Newbury House Publishers.

FISHMAN, J.; COOPER, R. \& ROSENBAUM, Y. (1977), "English around the world", in J. Fishman, R. Cooper e A. Conrad (orgs.), The spread of the english, Rowley (Massachusetts), Newbury House Publishers.

FLAITZ, Jeffra. (1988), The ideology of english: French perceptions of english as a world 
language. Berlim/Nova York/Amsterdan, Mouton de Gruyter.

FRIEDMAN, Jonathan. (2000), "Americans again, or the new age of a imperial reason?". Theory Culture and Society, 17 (1).

GLÄNZEL, W. (1976), "A bibliometric approach to social sciences: national research performances in 6 selected social sciences areas, 1990-1992". Scientometrics, 35 (3).

GÓMES, I.; SANCHO, R.; MORENO \& FERNÁNDEZ, M. T. (1999), "Influence of Latin American journals coverage by international databases". Scientometrics, 46 (3).

GREENBAUM, S. (org.). (1985), The english language today. Oxford, Pergamon Press.

HARRIS, Z. \& MATTICK, P. (1988), "Science, sublanguages and the prospects for a global language of science". The Annals of The American Academy of Political and Social Sciences, 495, jan.

HEILBRON, Johan. (1999), "Toward a sociology of translation: book translation as a cultural world-system". European Journal of Social Theory, 2 (4).

HOFFMANN, Charlotte (org.), Language, culture and communication in contemporary Europe. Clevedon (Grã-Bretanha), Multilingual Matters Ltd.

IANNI, Octávio. (1997), "A sociologia numa era de globalismo”, in L. Ferreira (org.), A sociologia no século XXI, São Paulo, Boitempo.

JABLONSKI, Nina \& AIELLO, Leslie (orgs.). (1998), "The origin and diversification of language". MEMOIRS of the California Academy of Science, 24, San Francisco.

KACHRU, Braj. (1982), "Models for non-native englishes", in B. Kachru (org.), The other tongue, Chicago, University of Illinois Press.

KISHIDA, K. \& MATSUI, S. (1997), "International publication pattern in social sciences: a quantitative analysis of the IBSS file". Scientometrics, 40 (2).
KROEBER, A. (1963), "Diffusionism", in Encyclopaedia of Social Sciences, Nova York, Macmillan Co., vol. 5

LARGE, J. A. (1983), The foreign language barrier: problems in scientific commmunication. Londres, Andre Deutsch.

LEVITT, Theodore. (1983), "The globalization of markets". Harvard Business Review, maio-jun.

McARTHUR, Tom. (1987), "The english language or the english languages?", in W. F. Bolton e D. Crystal (orgs.), The english language, Nova York, Peter Bedrick Books.

NARVAEZ-BERTHELEMOT \& RUSSEL, J. (2001), "World distribution of social science journals: a view from the periphery". Scientometrics, 51 (1).

ORTIZ, Renato (org.). (1983), Pierre Bourdieu. São Paulo, Ática.

. (1994), Mundialização e cultura. São Paulo, Brasiliense.

. (1996), Um outro território: ensaios sobre a mundialização. São Paulo, Olho d'Água.

. (2002), "Revisitando a noção de imperialismo cultural", in Josué Pereira da Silva (org.), Crítica contemporânea: cultura, trabalbo, politica, racismo, São Paulo, Annablume.

PARAKRAM, Arujna. (1995), De-Hegemonizing language standards. Londres, Macmillan Press.

PASSSERON, Jean Claude. (1995), O raciocínio sociológico. Petrópolis, Vozes.

PENNYCOOK, Alastair. (1994), The cultural politics of english as an international language. Londres, Longman.

(1998), English and the discourses of colonialism. Londres, Routledge.

PEREIRA DA SILVA, Josué (org.). (2002), Crítica contemporânea: cultura, trabalbo, politica, racismo, São Paulo, Annablume. 
PHILLILPSON, Robert. (1992), Linguist imperialism. Oxford, Oxford University Press.

(1999), "Voice in global english: unheard chords in Crystal, loud and clear". Applied Linguistics, 20 (2).

PHILLIPSON, Robert \& SKUTNABB-KANGAS, Tove. (1996), "English only worldwide or language ecology". Tesol Quartely, 30 (3).

REGUANT, S. \& CASADELLÀ, J. (1994), "English as lingua franca in geological scientific publications: a bibliometric analysis". Scientometrics, 29 (3).

RICENTO, Thomas (org.). (2000), Ideology, politics and language policies. Amsterdan/Philadelphia, John Benjamins Publishing Co.

ROBERTSON, Robert. (1992), Globalization: social theory and global culture. Londres, Sage Publications.

ROMANOS DE TIRATEL. (2000), "Conducta informativa de los investigadores argentinos en Humanidades y ciencias sociales". Revista Española de Documentación Científica, 23 (3).

RUSSELL, Jane. (1998), "Publishing patterns of Mexican scientists: difference between national and international papers". Scientometrics, 41 (1-2).

SINHA, S. (2000), "Science citation index: a failure under Indian scientific environment". Annals of Library Science and Documentation, 27 (2).

SONNTAG, Selma. (2000), "Ideology and policy in the politics of the English language in North India”, in Thomas Ricento (org.), Ideology, politics and language policies, Amsterdan/Philadelphia, John Benjamins Publishing Co.

STONE, S. (1982), "Humanities scholars: information needs and uses". Journal of Documentation, 38.

SWAAN, Abram de. (2001a), Words of the world. Cambridge, Polity Press. (2001b), "English in the social sciences", in Ulrich Ammon (org.), The dominance of english as a language of science, Berlim/Nova York, Mouton de Gruyter.

. (1991), "Notes on the emerging global language system: regional, national and supranational". Media Culture and Society, 14 (2).

TRUCHOT, Claude. (1990), L'anglais dans le monde contémporain. Paris, Robert.

TUNSTALL, Jeremy. (1977), The media are American. Nova York, Columbia University Press.

TSUNODA, Minoru. (1983), "Les langues internationales dans les publications scientifiques et techniques". Sophia Linguistica, 11.

VEGA, Josette de la. (2000), La communication scientifique à l'épreuve de l'internet. Paris, Presses de l'École Nationale Supérieure des Sciences de l'Information et des Bibliothèques.

"English only?". (1994), Sociolinguistica, 8 (tema da revista).

VESSURI, Hebe. (1995), "Recent strategies for adding value to scientific journals in Latin America”. Scientometrics, 34 (1).

WILLEY, T. G. \& LUKES, M. (1996), "English-only and standard english ideologies in the U.S.”. Tesol Quartely, 30 (3).

YITZHAKI, M. (1998), "The language preference in sociology: measures of language selcitation, relative own-language preference indicator, and mutual use of languages”. Scientometrics, 41 (1-2). 


\section{AS CIÊNCIAS SOCIAIS E O INGLÊS}

\section{Renato Ortiz}

\section{Palavras-chave}

Mundialização; Modernidade; Cultura; Identidade Nacional

O presente artigo é uma reflexão sobre o predomínio da língua inglesa no contexto da globalização, analisando particularmente as implicações desse fenômeno para as ciências sociais. Na primeira parte faz-se uma análise crítica da literatura elaborada pelos lingüistas em relação à expansão da língua inglesa no mundo contemporâneo, focalizando-se particularmente a passagem do inglês como língua internacional para $\mathrm{O}$ inglês como língua mundial. Na segunda, discute-se a supremacia do inglês nas ciências da natureza e nas ciências sociais. O argumento central é que essas duas práticas científicas são distintas, isto é, se o inglês pode funcionar como língua franca nas ciências da natureza, isso é impossível no âmbito das ciências humanas. Nesse sentido, como a construção do objeto social se faz por meio da língua, como ele encontra-se ainda referido a um contexto histórico-geográfico específico, a produção em ciências sociais deve manter uma pluralidade de idiomas na sua confecção. Porém, se o predomínio de uma língua se impõe, isso se dá em função de uma hierarquização de poder no mercado de bens lingüísticos, no interior do qual elabora-se uma falsa aproximação entre a idéia de universal e de global.

\section{SOCIAL SCIENCES AND THE ENGLISH LANGUAGE}

\author{
Renato Ortiz
}

\section{Keywords}

Globalization; Modernity; Culture; National identity.

The article analises the predominancy of the English language in the globalization context, particularly the implications related to the social sciences. It first makes a critical analysis of the literature elaborated by linguists concerning the expansion of the language in the contemporary world, focusing on the evolution of English from an international to a global language. It then discusses the supremacy of English both in natural and social sciences. The central argument is that such scientific practices are distinct, i.e., having English as lingua franca for natural sciences will make it impossible to have it doing so in the human sciences ambit. Assuming that the construction of the social object is achieved through the language, being it also referred to a specific historic-geographic context, the making of the social sciences must keep several languages in the process. The imposed prevalence of a language happens due to a power hierarchy in the linguistic métier, within which there has been an erroneous nearing between the ideas of universal and global.

\section{LES SCIENCES SOCIALES ET L'ANGLAIS}

\section{Renato Ortiz}

\section{Mots-clés}

Mondialisation; Modernité; Culture; Identité Nationale

Cet article est une réflexion à propos de la prédominance de l'anglais dans le contexte de la globalisation. L'auteur analyse, en particulier, les implications de ce phénomène sur les sciences sociales. Dans une première partie, il propose une analyse critique de la littérature élaborée par les linguistes par rapport à l'expansion de la langue anglaise dans le monde contemporain, s'attachant spécifiquement au passage de l'anglais, langue internationale, à l'anglais, langue mondiale. Dans la seconde partie, l'auteur discute la suprématie de l'anglais dans les sciences de la nature et les sciences sociales. L'argument central est que ces deux pratiques scientifiques sont distinctes, c'est-à-dire, si l'anglais peut fonctionner comme langue franche dans les sciences de la nature, cela est impossible dans le cadre des sciences humaines. Comme la construction de l'objet social se fait par la langue - car il se trouve toujours lié à un contexte historique et géographique spécifique la production dans les sciences sociales doit maintenir, dans son élaboration, une pluralité de langues. Néanmoins, si la prédominance d'une langue s'impose, cela a lieu en fonction de la hiérarchisation du pouvoir du marché de biens linguistiques à l'intérieur duquel se crée un faux rapprochement entre l'idée de l'universel et celle du global. 